\title{
Influence of inhomogeneity on several length scales on the local mechanical properties in V-alloyed all-weld metal
}

\author{
Phillip Haslberger $^{1}$ (D) $\cdot$ Wolfgang Ernst ${ }^{2} \cdot$ Christian Schneider $^{3} \cdot$ Sylvia Holly $^{4,5} \cdot$ Ronald Schnitzer $^{1}$
}

Received: 27 April 2018 / Accepted: 3 August 2018 / Published online: 13 August 2018

(C) The Author(s) 2018

\begin{abstract}
Recently, a new, vanadium alloyed welding consumable with a minimum yield strength of $1100 \mathrm{MPa}$ was developed. The mechanical properties of welding consumables for gas metal arc welding are usually classified by producing and testing allweld metal samples, which are typically a multipass weld. Chemical and microstructural fluctuations of a vanadium alloyed allweld metal sample on a macro- and microscale and their influence on the local mechanical properties were investigated. On a macroscale, hardness mappings show a pattern of hard and soft zones which can differ up to $60 \mathrm{HV}$. Despite the existence of these fluctuations, undersized Charpy V-notch tests revealed no significant difference between the last weld bead and the underlying ones. It is explained how vanadium and its tendency to form precipitates affect both the hardness inhomogeneity and the toughness homogeneity. On a microscale, segregations of several alloying elements and significant grain size fluctuations were found. Their influence on fluctuations of the mechanical properties is discussed as well.
\end{abstract}

Keywords Filler materials $\cdot$ Weld metal $\cdot$ Toughness $\cdot$ Hardness $\cdot$ Homogeneity $\cdot$ Multipass welding

\section{Introduction}

High-strength steels are frequently welded by gas metal arc welding with matching welding consumables to produce components with a high load bearing capacity and a comparatively low weight. These components can be found in e.g. vehicles or cranes, where a low component weight can save a significant amount of energy. The mechanical properties of the produced welds depend on their geometry, number of layers and the used welding parameters. Of course, also the choice of a suitable

Recommended for publication by Commission II - Arc Welding and Filler Metals

Phillip Haslberger

phillip.haslberger@unileoben.ac.at

1 Department of Physical Metallurgy and Materials Testing, Montanuniversitaet Leoben, Leoben, Austria

2 voestalpine Stahl GmbH, Linz, Austria

3 Institute of Materials Science, Joining and Forming, Graz University of Technology, Graz, Austria

4 voestalpine Böhler Welding Austria GmbH, Kapfenberg, Austria

5 Present address: voestalpine Wire Technology GmbH, Leoben, Austria chemical composition of the welding consumable is crucial. In order to classify the mechanical properties of the welding consumable itself, the production of all-weld metal samples according to DIN EN ISO 15792-1 is required. In this procedure, a large gap is buffered and then filled layer by layer with the welding consumable. The result is a multilayer structure similar to Fig. 1 with a reproducible number of beads depending on the chosen welding parameters. This sample design (and especially the buffering) eliminates influences from the chemical composition of the base material and should lead to a chemical composition of the weld metal which is only influenced by the chemical composition of the filler wire.

Such a multipass weld contains several sources of inhomogeneity on different scales. At first, the bead will solidify in a cellular or dendritic manner, which generates interdendritic segregations of alloying elements $[1,2]$. These segregations can affect the formation of different ferritic constituents in the weld metal during further cooling. This was described by Keehan et al. [2] for high-strength weld metals produced by shielded metal arc welding and by Powell and Herfurth [3] for gas metal arc welds. In another study, Haslberger et al. pointed out that these segregations could also influence the formation of clusters and precipitates in V-alloyed weld metal [4].

After delta ferrite formation, austenite columns will form upon cooling. Their size and shape may change throughout 


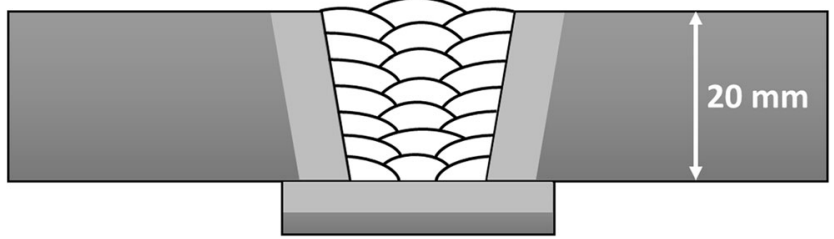

Fig. 1 Schematic of an all-weld metal sample for the investigated type of welding consumables. The area shaded light gray is the buffer zone

the weld bead. This phenomenon was investigated by Zhang and Farrar [5], who showed that the width of austenite columns can change throughout one weld bead depending on the nickel content. These factors (segregation and column growth) may influence the microstructure from a microscopic point of view.

From a macroscopic point of view, every deposited bead is reheated by subsequent welding passes. Depending on the peak temperature, this can effect remelting, reaustenitization, or tempering of the microstructure. As a result, zones with the original or altered microstructures exist in the weld, which was described in several studies [6-10]. The size of zones with different types of microstructure (i.e., columnar grains and refined equiaxed or recrystallized grains) is dependent on the used welding parameters [6]. The influence of the area fraction of columnar grains and recrystallized grains on the impact toughness is reported diversely [10]. While some indicated that a high amount of reheated material is beneficial for impact toughness [11], others suggested that a low amount of reheated material is advantageous because of a higher homogeneity of the weld [12]. Another study claimed that the influence of the amount of reheated material is negligible [3]. Therefore, it can be summarized that the influence of the amount of reheated material on the impact toughness strongly depends on the investigated material and its microstructural condition.

Currently, a V-alloyed welding consumable with a yield strength of $1100 \mathrm{MPa}$ and a minimum impact energy of $47 \mathrm{~J}$ at $-20{ }^{\circ} \mathrm{C}$ was developed [13]. The produced all-weld metal samples were martensitic and contained $\mathrm{V}(\mathrm{C}, \mathrm{N})$ precipitates $[4,13]$. The purpose of this study is to demonstrate the existence of chemical and microstructural inhomogeneities in this type of martensitic multipass weld metal and to clarify their influence on the mechanical properties of the weld. Special emphasis is put on the comparison between the last deposited bead and the middle of the all-weld metal due to their difference in thermal history. Hardness mappings and subsized Charpy V-notch tests are used to determine fluctuations of the local mechanical properties of the multipass weld. Microprobe investigations and microstructure comparisons are used to interpret the observed mechanical behaviour.

\section{Materials and methods}

The investigated all-weld metal samples were produced by gas metal arc welding according to DIN EN ISO 15792-1
Table 1 Used welding parameters for the production of all-weld metal samples

\begin{tabular}{lllll}
\hline Current (A) & Voltage (V) & $\begin{array}{l}\text { Welding speed } \\
(\mathrm{cm} / \mathrm{min})\end{array}$ & $\begin{array}{l}\text { Heat input } \\
\text { per unit length } \\
(\mathrm{kJ} / \mathrm{cm})\end{array}$ & $\begin{array}{l}\text { Interpass } \\
\text { temperature } \\
\left({ }^{\circ} \mathrm{C}\right)\end{array}$ \\
\hline 250 & 30 & 50 & 9 & 150 \\
\hline
\end{tabular}

using the welding parameters shown in Table 1. In total, the weld metal consisted of 7 layers with 21 beads (Fig. 1). The chemical composition of the weld metal is shown in Table 2. The amount of alloying elements guarantees a fully martensitic weld metal for the expected cooling time between 800 and $500{ }^{\circ} \mathrm{C}$ of about $5 \mathrm{~s}$. For an evaluation of the local mechanical behaviour of the weld metal, hardness mappings and local Charpy V-notch tests were carried out. The Vickers hardness mappings were conducted with a load of $2 \mathrm{~kg}$ and a step size of $0.5 \mathrm{~mm}$. Subsized Charpy $\mathrm{V}$-notch samples with a cross section of $5 \times 10 \mathrm{~mm}^{2}$ were prepared (Fig. 2), dividing the all-weld metal sample in an upper, middle and lower area. In the upper samples, a large part of the notch length was located in the last deposited bead, while the middle and lower samples contained a mixture of differently reheated material. Three samples were tested at each temperature according to DIN EN ISO 1481 , and the measured values were converted to the values for a $10 \times 10 \mathrm{~mm}^{2}$ sample by applying a geometric factor accounting for the size of the fractured area compared to a standard size sample [14].

For the investigations of interdendritic segregations, electron probe microanalysis measurements were performed at an acceleration voltage of $15 \mathrm{keV}$ and a probe current of $600 \mathrm{nA}$. A step size of $500 \mathrm{~nm}$ was chosen to ensure the ability to resolve the segregations. Light optical microscopy of the nital etched sample was used to identify zones with different microstructural appearance on a macro scale. Electron backscatter diffraction (EBSD) measurements at $30 \mathrm{keV}$ and $10 \mathrm{nA}$ with a step size of $80 \mathrm{~nm}$ were used to determine local effective grain sizes inside the last deposited bead. The effective grains were defined by their misorientation tolerance angle of $15^{\circ}[15]$, and their size was averaged by area. More information regarding sample preparation and EBSD parameters can be found in [16], which specifically addresses the microstructural characterization of all-weld metal samples with light optical microscopy and EBSD.

Table 2 Chemical composition of the investigated material ( $\mathrm{m} \%)$

\begin{tabular}{lllllllll}
\hline $\mathrm{C}$ & $\mathrm{Si}$ & $\mathrm{Mn}$ & $\mathrm{Cr}$ & $\mathrm{Mo}$ & $\mathrm{Ni}$ & $\mathrm{Cu}$ & $\mathrm{V}$ & $\mathrm{Fe}$ \\
\hline 0.08 & 0.57 & 1.27 & 0.78 & 0.73 & 3.03 & 0.11 & $0.2-0.5$ & Rest \\
\hline
\end{tabular}




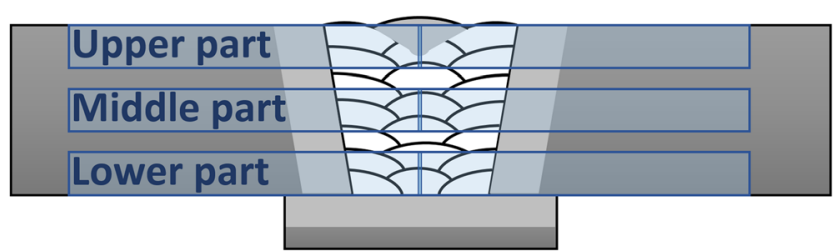

Fig. 2 Schematic of the prepared subsized Charpy V-notch samples. The approximate shape of the last weld bead is outlined

\section{Results}

\subsection{Local impact toughness}

The converted Charpy impact values from -60 to $+20{ }^{\circ} \mathrm{C}$ for all three locations in the multipass weld are depicted in Fig. 3. Generally, the impact toughness increases gradually with increasing temperature. There is no significant difference between upper, middle and lower part of the all-weld metal, and therefore no significant difference between top bead and tempered beads despite their diverse thermal history.

\subsection{Hardness mappings}

For an assessment of hardness fluctuations in the multipass welds, several hardness mappings were conducted over the whole weld metal, and the results are exemplarily shown on one obtained map. The hardness indents covered a large part of the sample, which is shown in Fig. 4a, where also the position of the last, untempered bead is marked by a black line. The position of the last bead is different compared to the sample used for the Charpy V-notch tests. However, this should not affect the interpretation of the results. The resulting hardness map is shown in Fig. 4b. Varying hardness values between 350 and $410 \mathrm{HV}$ were observed. The yellow and orange colours (arrow in Fig. 4b) in the last bead show that it is softer than the surrounding material. In the heat-affected zone below the last bead, a harder area with ca. $410 \mathrm{HV}$ and a soft zone with ca. $370 \mathrm{HV}$ follow. Throughout the rest of the all-weld metal, hard and soft zones appear in the shape of the

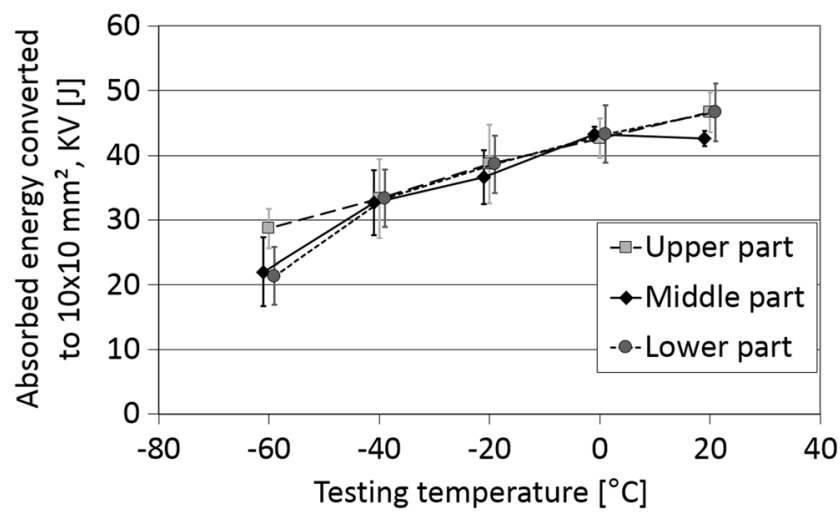

Fig. 3 Results of the subsized Charpy V-notch tests from -60 to $+20{ }^{\circ} \mathrm{C}$
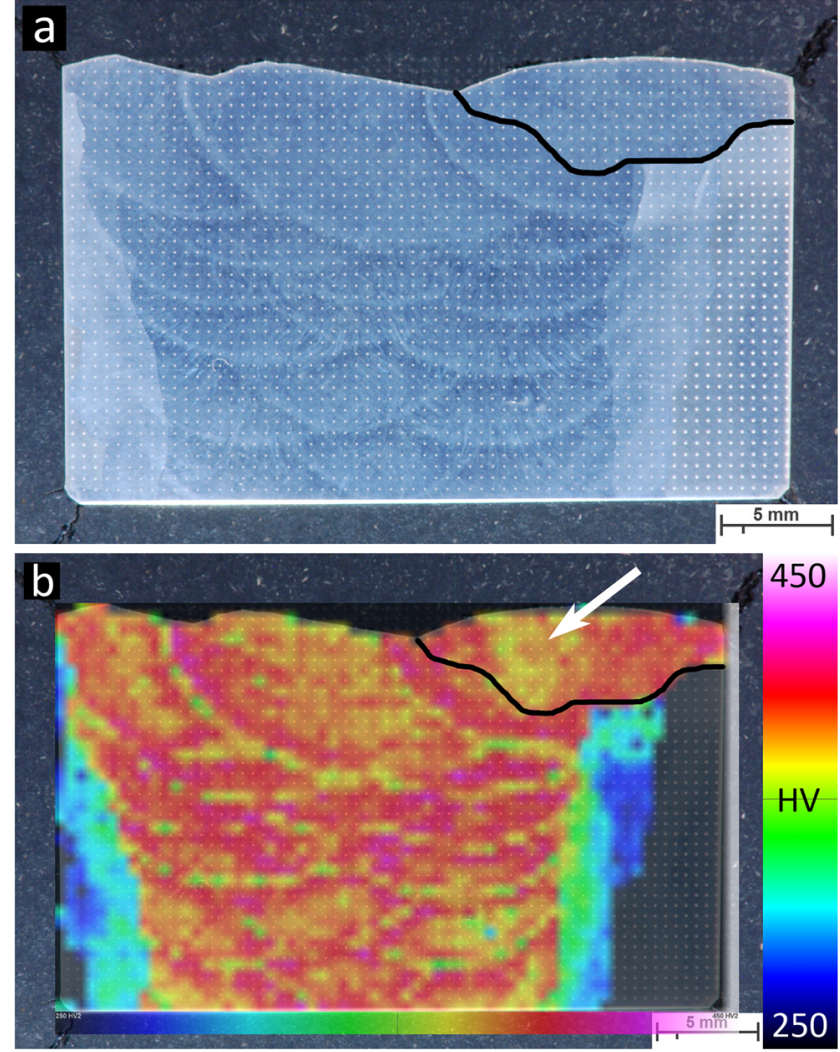

Fig. 4 a Nital etched all-weld metal sample after hardness mapping. The melting line of the last deposited bead is indicated by a black line. b Colour-coded hardness map of the V-alloyed sample superimposed on the image of the nital etched sample. The arrow points at the soft zone in the last weld bead

corresponding weld beads and their heat-affected zones, leading to an average hardness of ca. $380 \mathrm{HV}$.

\subsection{Interdendritic segregations}

Microprobe mappings of the elements $\mathrm{Mn}, \mathrm{Cr}$ and $\mathrm{V}$ were conducted to assess the existence and the amount of interdendritic segregation in the material. All measured elements clearly segregated, which is visible in Fig. 5. The red points in the Mn maps (Fig. 5a, b) originate from Mn-rich inclusions, which are homogeneously distributed over the whole weld metal. Consequently, they are not included in the further evaluation and interpretation of the interdendritic segregations visible in the map. Visually Mn segregates more than $\mathrm{Cr}$ (Fig. 5c, d) and V (Fig. 5e, f). The amount of segregation was evaluated by calculating the ratio of the maximum local element concentration and the average concentration over the whole map. Both $\mathrm{Mn}$ and $\mathrm{Cr}$ showed maximum contents of about $120 \%$ of the average value in the segregated regions. For V, this value was even higher with $190 \%$. No difference between the top bead and the middle beads was observed, implying that reheating did not cause a redistribution of alloying elements on this length scale. 
Fig. 5 Microprobe mappings of sample with $0.2 \mathrm{~m} . \% \mathrm{~V}$. The distributions of $\mathrm{Mn}(\mathbf{a}, \mathbf{b}), \mathrm{Cr}(\mathbf{c}$, d) and $\mathrm{V}(\mathbf{e}, \mathbf{f})$ are shown for the top bead and the middle beads, respectively
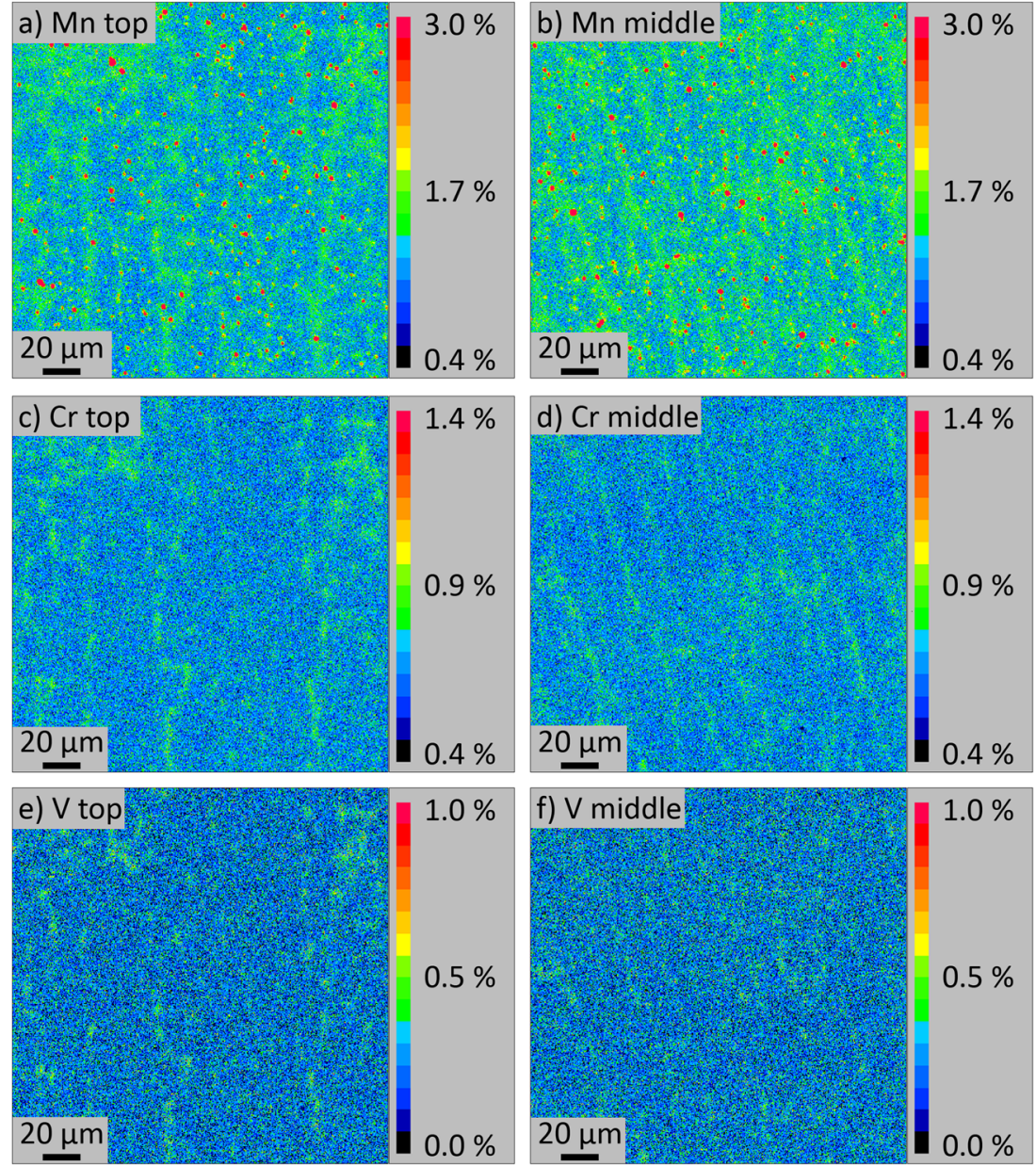

\subsection{Grain size fluctuations}

The nature of the multipass welding process implies the existence of grain size fluctuations between the passes due to reheating. This phenomenon of a mixture of zones with columnar grains and zones with equiaxed fine grains is well described in literature $[6,7,10,12,17,18]$ and exemplarily shown in Fig. 6 for the current material. On a different scale, grain size fluctuations inside a single weld bead may occur. Therefore, EBSD measurements were conducted at several positions in the last bead for a determination of the local effective grain size, which was defined by a tolerance angle of $15^{\circ}[15,19]$. This tolerance angle ensures that martensitic blocks are separated and that the grain size correlates to the fracture behaviour of the material [15]. The results in Table 3 clearly indicate the existence of fluctuations of the effective grain size within the bead. Additionally, due to the irregular nature of the martensitic microstructure, the standard deviation at each position is high. However, there was no evidence for changes in microstructure caused by the interdendritic segregations. The influence of the irregular microstructures on different scales will be discussed in the next section.

\section{Discussion}

Several methods were used to investigate the influence of inhomogeneity on different scales on the local mechanical

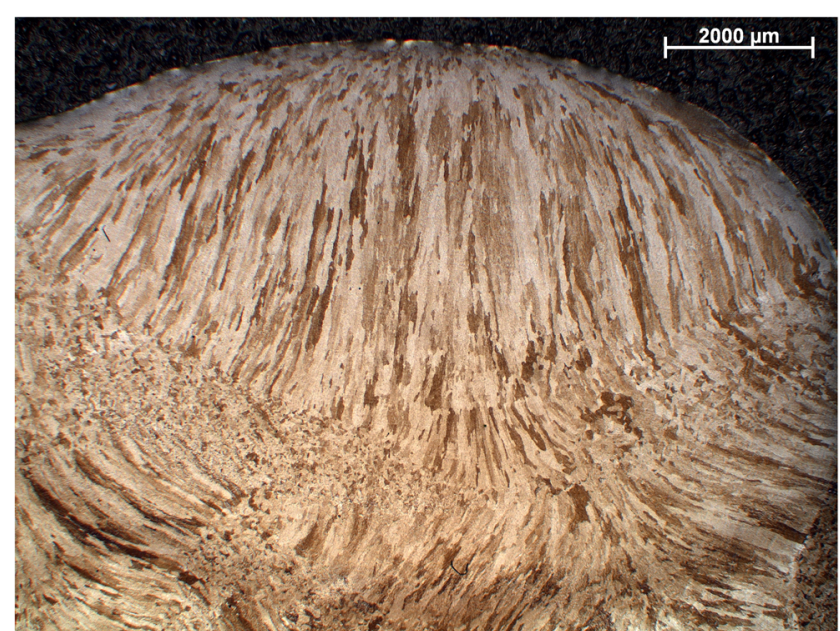

Fig. 6 Last deposited bead and its surroundings etched with nital. Below the bead, a zone consisting of equiaxed fine grains is visible 
Table 3 Local effective grain size in the last deposited bead depending on the distance to the fusion line

\begin{tabular}{ll}
\hline $\begin{array}{l}\text { Distance to the fusion } \\
\text { line }(\mathrm{mm})\end{array}$ & $\begin{array}{l}\text { Effective grain } \\
\text { size }(\mu \mathrm{m})\end{array}$ \\
\hline 0.52 & $2.6 \pm 1.6$ \\
2.4 & $2.7 \pm 1.4$ \\
2.5 & $3.1 \pm 2.1$ \\
3.8 & $2.8 \pm 1.6$ \\
3.9 & $2.8 \pm 1.7$ \\
\hline
\end{tabular}

properties of a martensitic all-weld metal sample produced from a new type of welding consumables.

In multipass welds, a weld bead will be heat treated by subsequent welding passes [7, 12]. In the case of a martensitic weld metal, this implies the assumption that the reheating will cause a tempering of the martensite which should generally increase the toughness [1]. Consequently, the last bead should have a higher strength and a lower toughness than the rest of the weld. However, the type of welding consumables investigated in this study is alloyed with $\mathrm{V}$. This element is known for its potent strengthening effect in steels because of its tendency to form precipitates during reheating $[4,20,21]$. Therefore, hardness mappings and local Charpy V-notch tests were applied to study the local mechanical properties and the difference between the last weld bead and the underlying beads in this type of material.

The local Charpy V-notch tests delivered unexpected results. From Fig. 3, it can be concluded that there is no significant difference between the impact toughness of the last bead (upper part) and the rest of the weld. Contrarily, the hardness mappings showed that the last bead is softer than the underlying structure (Fig. 4). This behaviour can be explained by looking at the precipitate population in the material. In an atom probe study on the same type of material [4], it was proven that precipitates do not exist in the last bead. Compared to the rest of the weld, the toughness is hence not decreased by precipitate formation, but also there is no tempering of the martensitic matrix. These counteracting mechanisms result in a parity of the Charpy V-notch energies for all parts of the weld. The absence of V-rich precipitates in the last bead is also responsible for its comparatively low hardness.

Both the impact energy and the hardness show significant fluctuations. The standard deviation of the impact energy was up to $6 \mathrm{~J}$ (Fig. 3). The hardness map depicts values between 350 and $410 \mathrm{HV}$ for the weld metal (Fig. 4). These fluctuations may stem from interdendritic segregations of alloying elements as well as grain size heterogeneity in the weld metal. As shown in Fig. 5, several alloying elements tend to segregate during solidification in the investigated system. The effect of these segregations on the martensitic matrix is hard to quantify. According to Table 3, the grain size varies depending on the location of the EBSD scan. However, there is no obvious evidence for a connection between interdendritic segregations and grain size. Nevertheless, it can be concluded that enrichments of elements like $\mathrm{Mn}, \mathrm{Cr}$ and especially $\mathrm{V}$ will change the potential for precipitate formation. The resulting heterogeneity of the precipitate population will induce fluctuations in the local impact energy.

Furthermore, as each welding pass will create a heataffected zone inside the weld metal with areas of coarsegrained microstructures and fine-grained microstructures, a multilayer weld is always inhomogeneous in terms of grain size. The intercritical reheated zone may also contain areas with fresh martensite which leads to a local deterioration of both hardness and toughness [22,23]. This soft zone is clearly visible in Fig. 4b. Additionally, the formation of precipitates is dependent on the reheating temperature. Hence, a Charpy Vnotch sample will contain a mixture of zones with different grain sizes (Fig. 6), microstructural constituents and precipitate populations, which may also lead to fluctuations in the impact energy values. Contrarily, Fig. 3 shows as high standard deviations for the top bead as for the rest of the weld. Therefore, it can be concluded that these heterogeneities in the middle of the multipass weld are balanced over a whole Charpy V-notch sample and the impact energy of the mixed microstructure will always be similar despite the existing hardness fluctuations.

\section{Conclusions}

An all-weld metal sample was produced by gas metal arc welding with a V-alloyed welding consumable, resulting in a multipass weld with 21 weld beads. This type of material was investigated regarding its local mechanical properties and microstructural appearance with local Charpy V-notch tests, hardness mappings, microprobe, light optical microscopy and electron backscatter diffraction. The findings can be summarized as follows:

- There was no significant difference between the local impact energies of the last bead and the underlying weld. The last bead does not contain precipitates, but is also not tempered. In the underlying weld, the tempering of the martensitic microstructure counteracts the toughness loss by precipitate formation.

- The hardness of the last bead was lower compared to the rest of the weld because of the absence of V-rich precipitates.

- Multipass welding produces heat-affected zones inside the weld with fluctuations of grain size and V-rich precipitate populations.

- Interdendritic segregations and effective grain size fluctuations are responsible for high standard deviations of the local impact toughness values. 
Acknowledgements Open access funding provided by Montanuniversität Leoben. The K-Project Network of Excellence for Metal JOINing is fostered in the frame of COMET-Competence Centers for Excellent Technologies by BMWFW, BMVIT, FFG, Land Oberösterreich, Land Steiermark, Land Tirol and SFG. The programme COMET is handled by FFG.

Open Access This article is distributed under the terms of the Creative Commons Attribution 4.0 International License (http:// creativecommons.org/licenses/by/4.0/), which permits unrestricted use, distribution, and reproduction in any medium, provided you give appropriate credit to the original author(s) and the source, provide a link to the Creative Commons license, and indicate if changes were made.

\section{References}

1. Grong O, Matlock DK (1986) Microstructural development in mild and low-alloy steel weld metals. Int Met Rev 31:27-48. https://doi. org/10.1179/imtr.1986.31.1.27

2. Keehan E, Karlsson L, Andrén H-O, Bhadeshia H (2006) New developments with C-Mn-Ni high-strength steel weld metals, part a-microstructure. Weld J 85:200s-210s

3. Powell GLF, Herfurth G (1998) Charpy V-notch properties and microstructures of narrow gap ferritic welds of a quenched and tempered steel plate. Metall Mater Trans A Phys Metall Mater Sci 29:2775-2784. https://doi.org/10.1007/s11661-998-0318-4

4. Haslberger P, Holly S, Ernst W, Schnitzer R (2018) Precipitates in microalloyed ultra-high strength weld metal studied by atom probe tomography. Weld World 62:713-719. https://doi.org/10.1007/ s40194-018-0581-y

5. Zhang Z, Farrar RA (1995) Columnar grain development in C-MnNi low-alloy weld metals and the influence of nickel. J Mater Sci 30:5581-5588. https://doi.org/10.1007/BF00356690

6. Yongyuth P, Ghosh PK, Gupta PC, Patwardhan AK, Prakash S (1992) Influence of macro/microstructure on the toughness of "all weld" multipass submerged arc welded C-Mn steel deposits. ISIJ Int 32:771-778

7. Reed RC, Bhadeshia HKDH (1994) A simple model for multipass steel welds. Acta Metall Mater 42:3663-3678. https://doi.org/10. 1016/0956-7151(94)90432-4

8. Mythili R, Thomas Paul V, Saroja S, Vijayalakshmi M, Raghunathan VS (2003) Microstructural modification due to reheating in multipass manual metal arc welds of 9Cr-1Mo steel. J Nucl Mater 312:199-206. https://doi.org/10.1016/S00223115(02)01680-X

9. Avazkonandeh-Gharavol MH, Haddad-Sabzevar M, Haerian A (2009) Effect of copper content on the microstructure and mechanical properties of multipass MMA, low alloy steel weld metal deposits. Mater Des 30:1902-1912. https://doi.org/10.1016/j. matdes.2008.09.023

10. Amrei MM, Monajati H, Thibault D, Verreman Y, Germain L, Bocher P (2016) Microstructure characterization and hardness distribution of $13 \mathrm{Cr} 4 \mathrm{Ni}$ multipass weld metal. Mater Charact 111: 128-136. https://doi.org/10.1016/j.matchar.2015.11.022

11. Jorge JC, Souza LF, Rebello JM (2001) The effect of chromium on the microstructure/toughness relationship of C-Mn weld metal deposits. Mater Charact 47:195-205. https://doi.org/10.1016/S10445803(01)00168-1

12. Bhadeshia HKDH, Svensson LE (1989) The microstructure of submerged arc-weld deposits for high-strength steels. J Mater Sci 24: 3180-3188. https://doi.org/10.1007/BF01139039

13. Haslberger P, Holly S, Ernst W, Schnitzer R (2018) Microstructure and mechanical properties of high-strength steel welding consumables with a minimum yield strength of $1100 \mathrm{MPa}$. J Mater Sci 53: 6968-6979. https://doi.org/10.1007/s10853-018-2042-9

14. Chao YJ, Ward JD, Sands RG (2007) Charpy impact energy, fracture toughness and ductile-brittle transition temperature of dualphase 590 steel. Mater Des 28:551-557. https://doi.org/10.1016/j. matdes.2005.08.009

15. Kim M-C, Jun Oh Y, Hwa Hong J (2000) Characterization of boundaries and determination of effective grain size in $\mathrm{Mn}-\mathrm{Mo}-\mathrm{Ni}$ low alloy steel from the view of misorientation. Scr Mater 43:205211. https://doi.org/10.1016/S1359-6462(00)00392-4

16. Haslberger P, Holly S, Ernst W, Schnitzer R (2017) Microstructural characterization of martensitic all-weld metal samples. Pract Metallogr 54:513-532. https://doi.org/10.3139/147.110464

17. Kikuta Y, Araki T, Yoneda M, Yoshida H, Suga T (1982) The reheated zone toughness of multipass weld metal (report 1). J Japan Weld Soc 51:359-365. https://doi.org/10.2207/qjjws1943. 51.359

18. Surian E, Ramini de Rissone M, De Vedia L (2005) Influence of molybdenum on ferritic high- strength SMAW all-weld-metal properties. Weld J 84:53-62

19. Mine Y, Hirashita K, Takashima H, Matsuda M, Takashima K (2013) Micro-tension behaviour of lath martensite structures of carbon steel. Mater Sci Eng A 560:535-544. https://doi.org/10. 1016/j.msea.2012.09.099

20. Gladman T (1997) The physical metallurgy of microalloyed steels. The Institute of Materials, London

21. Lagneborg R, Siwecki T, Zajac S, Hutchinson B (1999) The role of vanadium in microalloyed steels. Scand J Metall

22. Akselsen OM, Solberg JK, Grong O (1988) Effects of martensiteaustenite (M-A) islands on intercritical heat-affected zone toughness of low carbon microalloyed steels. Scand J Metall 17:194-200

23. Matsuda F, Ikeuchi K, Fukada Y et al (1995) Review of mechanical and metallurgical investigations of MA constituent in welded joint in Japan. Trans JWRI 24:1-24 